DOE-PC-91308-1

\title{
PARTICULATE BEHAVIOR IN A CONTROLLED-PROFILE PULVERIZED COAL-FIRED REACTOR: A STUDY OF COUPLED TURBULENT PARTICLE DISPERSION AND THERMAL RADIATION TRANSPORT
}

Quarterly Technical Progress Report For Period September 15, 1990 to December 14, 1990

Mrit 10 igus

\author{
Mardson Queiroz and Brent W. Webb \\ Brigham Young University \\ Provo, UT 84602
}

\section{Prepared for the United States Department of Energy Pittsburgh Energy Technology Center (PETC)}

Under Contract No. DE-FG22-91PC,91308

"US/DOE Patent Clearance is not required prior to the publication of this document"

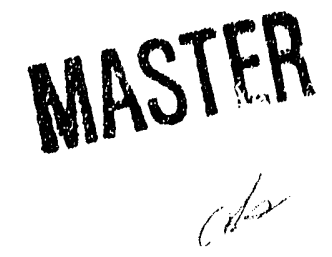




\section{DISCLAIMER}

This report was prepared as an account of work sponsored by the United States Government. Neither the United States nor the United States Department of Energy, nor any of their employees nor any of their contractors, subcontractors, or their employees, makes any warranty, expressed or implied, or assumes any legal liability or responsibility for the accuracy, completeness, or usefulness of any information, apparatus, product or process disclosed, or represents that its use would infringe privately owned rights. 


\section{FORWARD}

This report summarizes technical progress during the first quarter (September 15, 1990 to December 14, 1990) of a three-year study conducted for the Department of Energy (DOE) under contract number DE-FG22-91PC91308. The principal investigators for this work are Dr. Mardson Queiroz and Dr. Brent W. Webb; Dr. Clifford Smith is the technical representative for DOE. 
DISCLAIMER

FORWARD

1. OBJECTIVES AND SCOPE $\quad 1$

1.1 BACKGROUND

1.2 OBJECTIVES

1.3 TECHNICAL APPROACH

\section{1 \\ 1}

2. SUMMARY OF TECHNICAL PROGRESS 2

2.1 LITERATURE REVIEW

2.2 INSTRUMENTATION ACQUISITION AND DEVELOPMENT

2.3 GRADUATE STUDENT RECRUITMENT

3. REFERENCES

4. APPENDIX 


\begin{abstract}
During the first quarter progress has been made in the following areas: literature review, instrumentation acquisition and development and graduate student recruitment. The nearly-finished Ph.D. dissertations of two graduate students from this laboratory will provide a thorough review of prior work in the areas covered by this project. This information will serve to guide the project emphasis and matrix of test conditions. A particle counter sizer velocimeler probe to measure particle size, velocity and number density was purchased. Two suction pyrometers of different lengths, a hemispherical radiometry probe and a total heat flux probe have also been acquired to perform gas temperature and radiationrelated measurements. These purchases were made with funds from other sources but will support the effort of this project substantially. Finally, one Ph.D. student with experience in the BYU reactor has been recruited. Recruiting efforts will continue for one more Ph.D. student.
\end{abstract}




\section{OBJECTIVES AND SCOPE}

\subsection{BACKGROUND}

Improved understanding of the fundamental processes involved in pulverized-coal combustion is needed to make the energy extraction more efficient and the combustion byproducts environmentally safe. While the characterization of the local particulate behavior (concentration, size, and velocity) is important to the understanding of virtually all processes in a pulverized coal-fired furnace, it influences in a more direct way the turbulent particle dispersion and thermal radiation heat transfer. Yet the local particulate dynamics have gone relatively unaddressed, primarily because of lack of adequate instrumentation to carry out such a study. With recent advances in optical techniques such an effort is now possible. This proposal seeks to characterize the local particulate concentration, velocity, and size distribution in a wellcontrolled, parametrically-varied laboratory-scale reactor using a new laser diagnostic technique. This newly-developed technique is the only one currently available for the investigation of aspherical particles. The particulate data will be collected simultaneously with local gas temperature and wall radiant heat flux distributions.

\subsection{OBJECTIVES}

This report describes recent progress in a fundamental, three-year investigation of the coupled problem of turbulent particle dispersion and thermal radiation transport. The project's objective is to make measurements of particle size, velocity, number density, temperature and wall radiant heat flux in a parametrically-controlled reactor presently existent at Brigham Young University (BYU). Although the study proposed here is primarily designed to provide experimental data not currently available for the evaluation of turbulent particle dispersion and radiation models, comparisons of analytical predictions and the experimental data obtained will be performed, using appropriate submodels integral to comprehensive pulverized-coal combustion codes existent at BYU.

\subsection{TECHNICAL APPROACH}

To accomplish thie above objectives, the project is divided in the following tasks:

- Design and fabrication of a modified section for the BYU controlled-profile reactor, which will allow access of several probes to be used in the proposed study.

- Design and fabrication of a two-color pyrometer and cooled probe for local particulate temperature measurement.

- Characterization of the non-reacting turbulent flow field in the reactor using the PCSV-P probe, which will serve as an input during the turbulent particle dispersion submodel validation.

- Literature review dealing with particle Jispersion and radiation transport in support of the model valida. tion effort. 
- Pertorm the parametrically-controlled measurements in the controlled-profile reactor.

- Experimental data analysis.

- A comprehensive comparison of experimental data and model predictions.

- Final report.

\section{SUMMARY OF TECHNICAL PROGRESS}

\subsection{LITERATURE REVIEW}

Considerable work exists dealing with areas relevant to this project. Prior investigations dealing with turbulent particle dispersion and radiation transport are numerous in the literature. Two Ph.D. candidates from this laboratory working in areas related to this siudy are completing their work. A significant contribution of their work has been a thorough review of prior work in the area (Bonin, 1992; Butler, 1992). This information will serve to guide the project emphasis, generally, and matrix of experimental test conditions, specifically.

\subsection{INSTRUMENT ALQUISITION AND DEVELOPMENT}

The proposed experimental work is instrumentation-intensive, and some of the equipment proposed for use is being developed or acquired. This section summarizes the acquisitions made and progress in the development of new diagnostic tools.

\section{Particle Sizing}

Non-intrusive optical techniques for the characterization of droplets and particles in reacting and non-reacting systems has been under development for some time. The approach adopted in this project is the only technique capable of making measurements on non-spherical particles. The Insitec Particle Counter Sizer Velocimeter Probe (PCSV-P) is a laser-based tool designed for the simultaneous measurement of particle concentration, size, and velocity. With other funding, such a tool has been acquired for use on this project. Over the past several months the irıstrument has been used in characterizing particulate behavior in an industrial-scale coal-fired boiler (Bonin and Queiroz, 1991; Bonin and Queiroz, 1992). The work in the full-scale environment provided opportunity for equipment checkout and familiarity, necessary to carry out the work proposed. The current effort is the design of a test matrix and facility modification to accommodate the probe.

\section{Suction Pyrometry}

The use of suction pyrometry for the meajurement of local gas phase temperature is wellunderstood. Briefly, the technique involves the high-velocity suction of combustion gases through a series of ducts past a thermocouple. The ducts are formed by triple ceramic radiation shields which reduce significantly the radiation error. The laboratory here has acquired suction pyrometers of two 
lengths, and the measurement technique has been used in both small-scale and full-scale environments. Associated experimental errors have been assessed for the tool's use in a dusty flame (Butler and Webb, 1991: Butler, 1992). Suction pyrometry will be used to characterize the temperature field in the work.

Hemispherical Radiometry and Total Heat Flux

Local wall radiative flux and total flux data are of interest in the validation of both comprehensive models and specific submodels. These measurements are made with hemispherical radiometry and total heat flux probes, both of which have been acquired under separate funding for use on this project. Besides model validation, the probes will provide critical information relative to radiation-convection partitloning.

\section{Two-Color Pyrometry}

Coal particle temperature is a parameter critical to many facets of a comprehensive modeling scheme. It reflects on the kinetics of the solid phase reaction, the gas phase mixing, and the radiation heat transfer, to name a few. The measurement of particulate phase temperature was proposed in this project. A two-color pyrometer has been developed for the measurement of quasi-local particulate temperatures. The term quasi-local is used because the instrument measures particle cloud temperatures. That cloud is isolated from the surrounding field and is imaged by optics at the two wavelengths. An industrial-scale version of the instrument has been used for time-resolved particle temperature measurements in a full-scale utility boiler (Butler et al., 1992; Butler and Webb, 1992). Combined with the measurement of gas phase temperature, the two-color pyrometer measurements will provide valuable information relative to local gas-particle temperature differences in the Controlled Profile Reactor for this project.

\subsection{GRADUATE STUDENT RECRUITMENT}

One high priority of the work for the past quarter has been the recruitment of Ph.D. students. To date, one student has committed for work in the lab. This student has extensive experience in combustion modeling, and, having done his M.S. work here in the laboratory, has gained lamiliarity with the instrumentation and reactor operation. A second Ph.D. student has yet to be found, but recruiting efforts will continue. 


\section{REFERENCES}

Bonin, M.P. (1992). "Optical Measurement of Particle Size, Velocity and Number Density in Pulverized Coal Flames," Ph.D. Dissertation, Mechanical Engineering Department, Brigham Young University

Bonin, M.P., and Queiroz, M. (1991). "Local Particle Velocity, Size and Concentration in an Industrial Scale Pulverized Coal Fired Boiler," Combustion and Flame 85:121-133.

Bonin, M.P., and Queiroz, M. (1992). "A Parametric Evaluation of Particle Dynamics in a Full-Scale, Pulverized Coal-Fired Boiler," Submitted to the 24th Symposium (International) on Combustion.

Butler, B.W., and Webb, B.W. (1991). "Local Temperature and Wall Radiant Heat Flux Measurements in an Industrial Scale Coal Fired Boiler," Fuel 70:145-1464.

Butler, B.W., and Webb, B.W. (1992). "Measurement of Local Gas and Particle Temperature, and Wall Heat Flux in an Industrial-Scale Coal-Fired Boiler," Submitted to the 24th Symposium (International) on Combustion.

Butler, B.W., Wilson, T., and Webb, B.W. (1992). "Measurement of Time-Resolved Local Particle Temperature in a Full-Scale Utility Boiler," Submitted to the 24th Symposium (International) on Combustion.

Butler, B.W. (1992). "Experimental Characterization of Radiant Energy Transfer in Particle-Laden Flames," Ph.D. Dissertation, Mechanical Engineáring Department, Brigham Young University. 

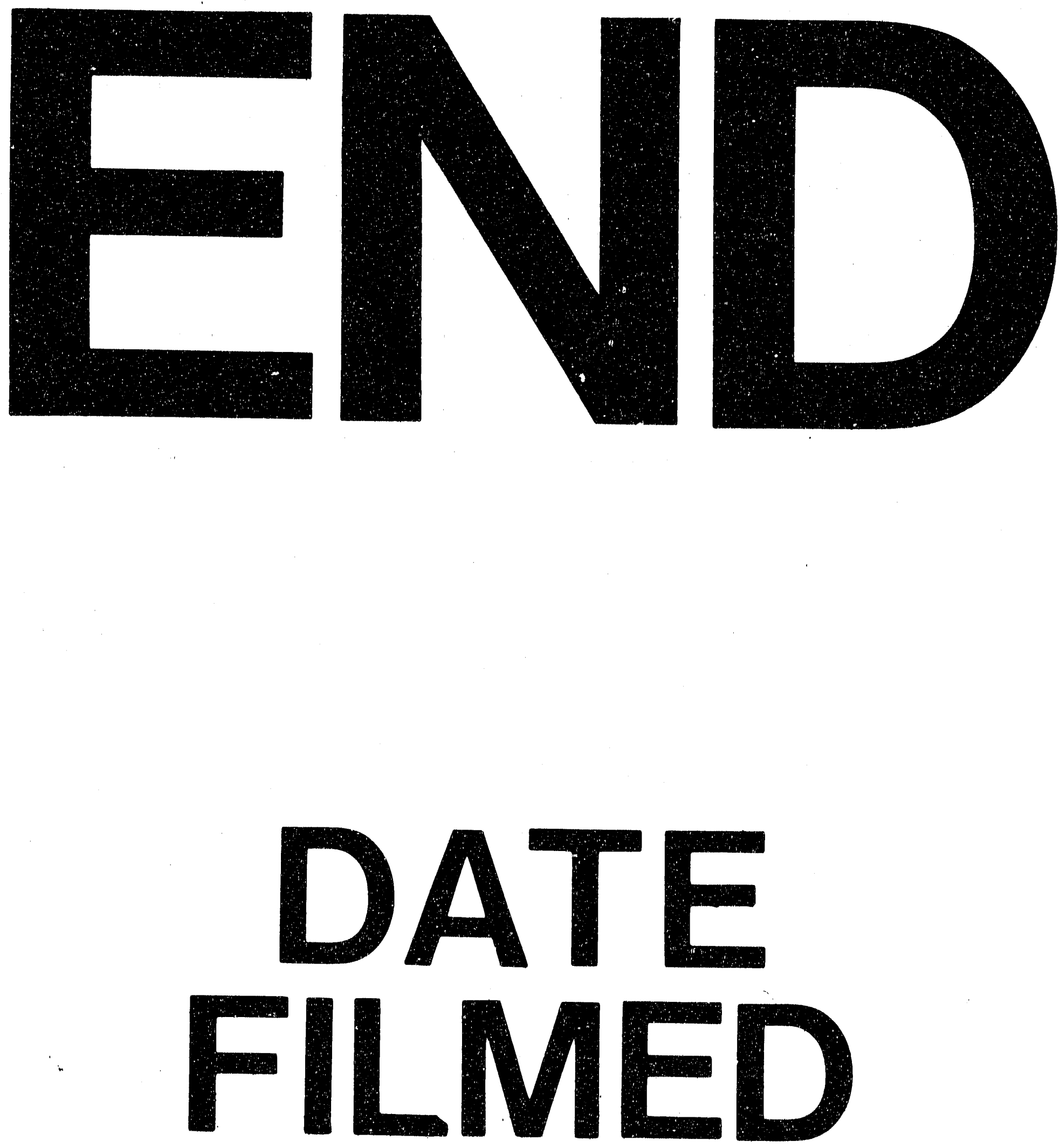

4
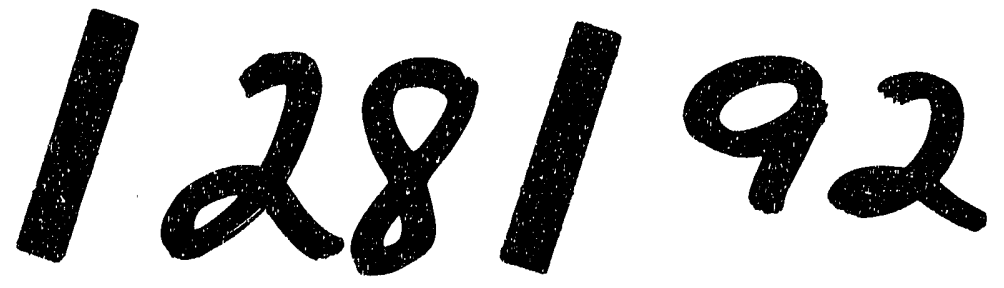
